\title{
Factors potentially affecting fertility of lactating dairy cow recipients
}

\author{
J.L.M. Vasconcelos ${ }^{\text {a,* }}$, D.G.B. Demétrio ${ }^{\text {a,b }}$, R.M. Santos ${ }^{\text {c }}$, \\ J.R. Chiari ${ }^{\text {b }}$, C.A. Rodrigues ${ }^{\mathrm{d}}$, O.G. Sá Filho ${ }^{\mathrm{a}}$

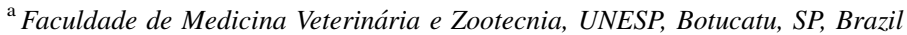 \\ ${ }^{\mathrm{b}}$ Samvet Embriões, Centro de Biotecnologia da Reprodução de Bovinos, Morrinhos, GO, Brazil \\ ${ }^{\mathrm{c}}$ Faculdade de Ciências Agrárias e Veterinárias, UNESP, Jaboticabal, SP, Brazil \\ ${ }^{\mathrm{d} C l i ́ n i c a}$ Veterinária Samvet, São Carlos, SP, Brazil
}

\begin{abstract}
Objectives of this study were to evaluate factors that could affect pregnancy rate after embryo transfer (ET) in lactating dairy cow recipients. The trial was conducted at a dairy farm located in Descalvado, SP, Brazil from October 2003 to September 2004. From 1037 cows with CL that were treated with an injection of $\mathrm{PGF}_{2 \alpha}, 43.3 \%$ were detected in heat; 263 were previously assigned at day of $\mathrm{PGF}_{2 \alpha}$ injection for AI and 186 for ET. Ovulation rate was $85.7 \%$ (385/449). Pregnancy rate for cows with CL for AI and embryo transfer recipients were $36.5 \%(84 / 230)$ and $58.7 \%$ (91/155) at day 25 and $33.0 \%$ (76/230) and 45.8\% (71/155) at day 46, respectively. Embryonic loss were $9.5 \%(8 / 84)$ for the AI group and $21.9 \%$ (20/91) for the ET group. Average milk production was $31.4 \mathrm{~L} /$ day/cow. Average daily milk production from 7 days before $\mathrm{PGF}_{2 \alpha}$ injection to 7 days after ET tended $(P<0.10)$ to influence pregnancy rate on days 25 and 46 . Average daily milk production from the day of embryo transfer to 7 days after influenced embryonic loss $(P<0.05)$. Cows with higher milk production had lower probability of pregnancy and higher probability of embryonic loss. Cows with higher days in milk had higher probability of pregnancy. Cows with higher rectal body temperature had lower probability of pregnancy and higher probability of embryonic loss. The influence of high milk yield and body temperature on fertility in lactating dairy cow recipients suggests that these effects can occur also after embryo reaches the blastocyst stage.
\end{abstract}

(C) 2005 Elsevier Inc. All rights reserved.

Keywords: Embryo transfer; Milk; Cows; Heat stress; Pregnancy rate

\footnotetext{
* Corresponding author at: Departamento de Produção Animal, FMVZ, Unesp, Botucatu, SP, Brazil. Tel.: +55 14 38117189/209.

E-mail address: vasconcelos@fca.unesp.br (J.L.M. Vasconcelos).
} 


\section{Introduction}

Many factors influence fertility including cyclicity, energy balance, heat stress, parity, milk production, diet and diseases [1-6]. Reproductive efficiency in lactating dairy cows has declined and has been associated with a steady increase in average milk production per year [7]. The reproductive performance of lactating cows under high environmental temperature is compromised because of the deleterious effect of heat stress on fertilization and embryo survival [8].

Embryo transfer has become the most powerful tool animal breeders have acquired since AI. Multiple ovulation and embryo transfer (ET) was used initially to produce more embryos from genetically elite cows in shorter time periods [9]. Today, it is also used as a method to attenuate some of detrimental effects of heat stress on fertility [10-12].

Objectives of this study were to evaluate factors that could affect pregnancy rate after ET in lactating dairy cow recipients.

\section{Materials and methods}

The experiment was conducted at a commercial dairy farm located in Descalvado, São Paulo, Brazil from October 2003 to September 2004. A total of 1037 lactating Holstein cows with 50-547 days in milk (DIM) were used from a 1200-cow milk herd. Animals were maintained in a freestall barn with access to an adjoining sod-based area. Barns were cooled to minimize the effects of heat by intermittent sprinkling and forced ventilation. Cows were milked three times a day and feed with a total mixed ration based on corn silage and balanced to meet nutritional requirements for lactating dairy cows. Daily milk yield for each cow was recorded (Alpro Transponder ${ }^{\circledR}$, De Laval, Brazil). Average daily milk yield from 7 days before $\mathrm{PGF}_{2 \alpha}$ injection to 7 days after ET was recorded and divided in periods: 7 days before $\mathrm{PGF}_{2 \alpha}$ injection; from day of $\mathrm{PGF}_{2 \alpha}$ injection to day of embryo transfer and from day of embryo transfer to 7 days latter.

Nonpregnant cows were evaluated once a month (at Fridays); when a CL was palpated per rectum, cows were treated with $\mathrm{PGF}_{2 \alpha}\left(25 \mathrm{mg}\right.$ dinoprost tromethamine; Lutalyse ${ }^{\circledR}$; Pharmacia Animal Health, Kalamazoo, MI, USA) and randomly assigned to receive AI or ET. Cows in the AI group were inseminated as they showed estrus $48-96 \mathrm{~h}$ after $\mathrm{PGF}_{2 \alpha}$ injection. Cows in the ET group that showed estrus $48-96 \mathrm{~h}$ after $\mathrm{PGF}_{2 \alpha}$ injection (Sunday-Tuesday), received one embryo at 6, 7 or 8 days after estrus, next Monday (10 days after $\mathrm{PGF}_{2 \alpha}$ injection). Only results of ET are discussed in this paper.

Embryos were obtained from a commercial company (Samvet Embriões, Descalvado, Brazil). Embryos were evaluated at $50 \times$ under a stereomicroscope and placed in TQC holding solution (AB Technology, Nutricell, Brazil), maintained at ambient temperature. Only grades 1 and 2 morulae, early blastocysts and mid-blastocysts were designated for fresh transfer [13]. They were collected nonsurgically from superovulated, non-lactating Holstein cows. On-farm transfer of fresh embryos was possible because of the synchronization of estrous cycles of donors and recipients. Prior to transfer, recipients were evaluated by ultrasound (Aloka SSD 500 V; Aloka Co. Ltd., Tokyo, Japan) equipped with a $5 \mathrm{MHz}$ linear transrectal probe to determine the presence of the CL. After epidural 
anesthesia, embryos were transferred nonsurgically to the uterine horn ipisilateral to the CL by a veterinarian experienced in embryo transfer.

Rectal body temperature was recorded on day of embryo transfer and 7 days latter. Blood samples were collected on day of embryo transfer and 7 days latter by coccygeal venipuncture into $10 \mathrm{~mL}$ heparinized Vacutainer ${ }^{\circledR}$ tubes. Tubes were placed in ice immediately after blood collection, centrifuged $(1000 \times g, 15 \mathrm{~min})$ within $6 \mathrm{~h}$ and plasma separated. Plasma samples were stored at $-20{ }^{\circ} \mathrm{C}$ until analysis for progesterone by radioimmunoassay (Coat a Count ${ }^{\circledR}$ Diagnostic Products Corporation, Los Angeles, CA). The intra and inter assay CVs were $6.2 \%$ and $7.9 \%$, respectively, and sensibility was $0.01 \mathrm{ng} / \mathrm{mL}$.

Pregnancy diagnosis was performed by ultrasonography at day 24-26 after estrus (pregnancy rate day 25). Pregnant cows were reevaluated by ultrasonography at day 45-47 after estrus (pregnancy rate day 46). Embryonic loss was considered when cows pregnant on day 25 were not pregnant on day 46.

The binary variables pregnancy rates at days 25 and 46, and embryonic loss rates were analyzed by binary logistic regression, and the continuous variable rectal body temperature on day of ET was analyzed by GLM, using MINITAB [14]. The mathematical model included the effects of average daily milk production at different intervals related to the day of $\mathrm{PGF}_{2 \alpha}$ injection and day of ET, DIM, rectal body temperature, plasma progesterone concentration and season. Linear, quadratic and cubic effects were tested. Treatment differences with $P \leq 0.05$ were considered significant, while tendencies were considered when $P>0.05$ and $\leq 0.10$.

\section{Results}

A total of 1037 cows with a CL received an injection of $\mathrm{PGF}_{2 \alpha}$. Of these, $449(43.3 \%)$ were detected in estrus, and 263 were assigned for AI and 186 for ET. Thirty-one cows that

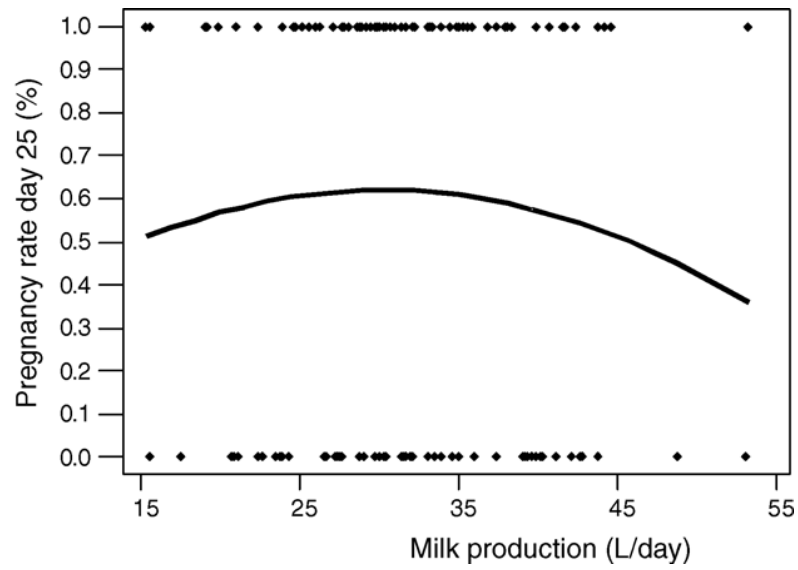

Fig. 1. Effect of milk production (average milk production from 7 days before $\mathrm{PGF}_{2 \alpha}$ injection to 7 days after ET) on estimated probability of pregnancy at day 25 in lactating dairy cow recipients (dots are the distribution of events: $0=$ not pregnant; 1 = pregnant). 
had been assigned for ET did not receive an embryo because there was no CL on day 7. Thirty-three cows that had been assigned for AI did not have a CL on day 7. Ovulation rate of all cows was $85.7 \%(385 / 449)$.

Pregnancy rate (cows with CL on day 7 after estrus) for AI and embryo transfer recipients were $36.5 \%(84 / 230)$ and $58.7 \%(91 / 155)$ at day 25 and $33.0 \%(76 / 230)$ and $45.8 \%(71 / 155)$ at day 46, respectively. Embryonic loss were $9.5 \%(8 / 84)$ for the AI group and $21.9 \%$ (20/91) for the ET group.

Average milk production of recipient cows was $31.4 \mathrm{~L} /$ day. There was a tendency for average milk production from 7 days before PGF $_{2 \alpha}$ injection to 7 days after ET to influence pregnancy rate at day $25(P<0.10)$ and day $46(P<0.10)$. Average daily milk production from the day of embryo transfer to 7 days later influenced embryonic loss $(P<0.05)$. Cows with higher milk production tended to have a lower probability of pregnancy (Figs. 1 and 2 ) and had a higher probability of embryonic loss (Fig. 3).

Average days in milk for recipients were 189 days. Days in milk influenced pregnancy rate at day $46(P<0.05)$. Cows with higher days in milk had a higher probability of pregnancy (Fig. 4).

The average milk production from 7 days before $\mathrm{PGF}_{2 \alpha}$ injection to 7 days after ET had tendency $(P=0.08)$ to influence rectal body temperature on day of embryo transfer.

Rectal body temperature at 7 days after estrus influenced pregnancy rate at day 25 $(P<0.05)$ and tended to influence pregnancy rate at day $46(P<0.10)$ and embryonic loss $(P<0.10)$. Cows with higher body temperature had a lower probability of pregnancy (Figs. 5 and 6) and higher probability of embryonic loss (Fig. 7).

There was no difference on pregnancy rate and embryonic loss rates among seasons. Circulating plasma progesterone concentration also did not influence pregnancy rate or embryonic loss.

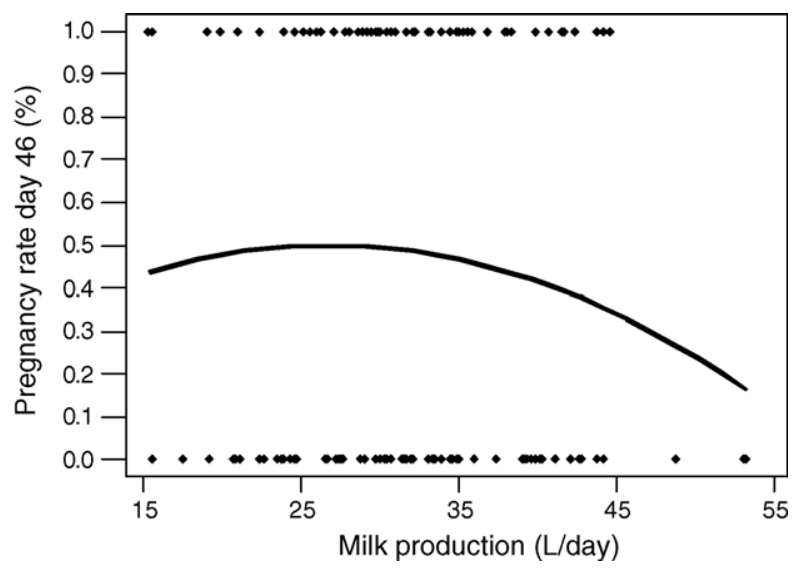

Fig. 2. Effect of milk production (average milk production from 7 days before $\mathrm{PGF}_{2 \alpha}$ injection to 7 days after ET) on estimated probability of pregnancy at day 46 in lactating dairy cow recipients (dots are the distribution of events: $0=$ no loss; $1=$ loss). 


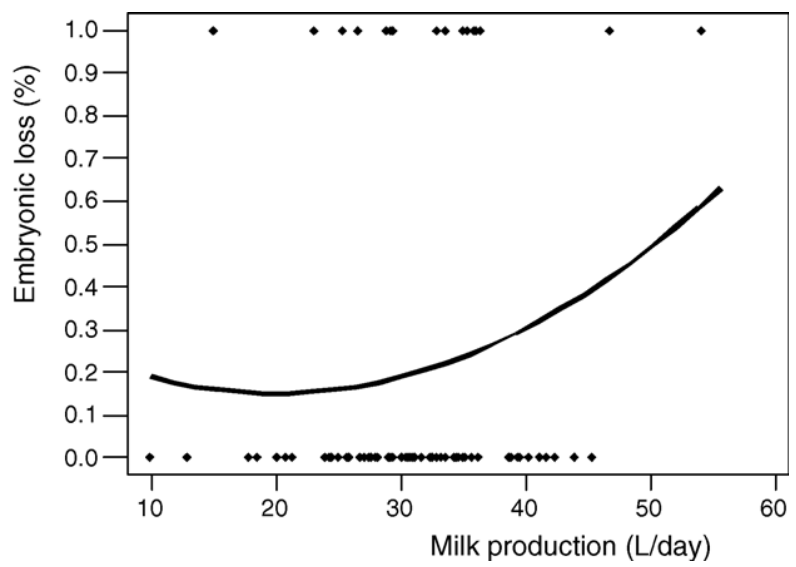

Fig. 3. Effect of milk production (average milk production from the day of embryo transfer to 7 days latter) on estimated probability of embryonic loss in lactating dairy cow recipients (dots are the distribution of events: $0=$ no embryonic loss; 1 = embryonic loss).

\section{Discussion}

Environmental and stress factors promote ovulation failure, which is considered to be a cause of infertility in dairy cattle [15]. In this study, there was an estimated rate of ovulation failure of $14.3 \%$. One advantage of embryo transfer is that presence of the CL is evaluated before transferring the embryo.

The pregnancy rates of $58.7 \%$ at day 25 and $45.8 \%$ at day 46 are higher than for most papers using lactating recipients $[10,12]$. The high pregnancy rates may reflect the fact that fresh, in vivo-produced embryos from non-lactating dairy cows were transferred. Sartori

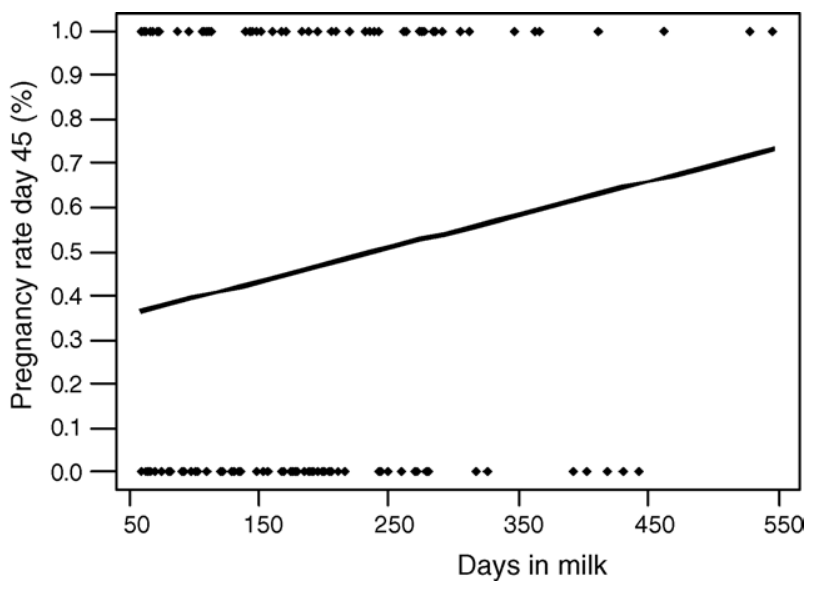

Fig. 4. Effect of days in milk on estimated probability of pregnancy at day 46 in lactating dairy cow recipients (dots are the distribution of events: $0=$ not pregnant; $1=$ pregnant). 


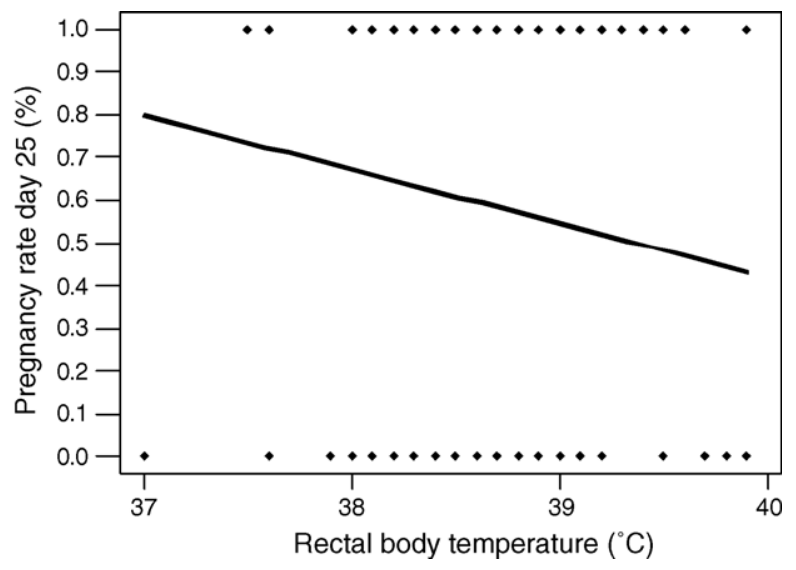

Fig. 5. Effect of rectal body temperature on day of embryo transfer on estimated probability of pregnancy at day 25 in lactating dairy cow recipients (dots are the distribution of events: $0=$ not pregnant; $1=$ pregnant).

et al. [16] reported a very high percentage of non-viable embryos ( $\sim 70 \%$ during summer and $\sim 50 \%$ during winter) by day 6 after estrus as compared to heifers during summer ( $\sim 30 \%$ non-viable embryos) and non-lactating cows during winter $(\sim 20 \%$ non-viable embryos). Bode et al. [17] evaluated the effects of protein intake on early embryo development in lactating dairy cows, and reported no differences in the quantity, visual quality, or stage of development of embryos collected from cows with low plasma urea nitrogen (PUN) or cows with high PUN, but embryos from cows with low PUN resulted in higher pregnancy rate than the embryos from cows with high PUN. These data suggest that despite the same visual quality, some embryos may have intrinsic problems.

The $21.9 \%$ rate of embryonic loss was similar to values found by some authors $[7,18]$.

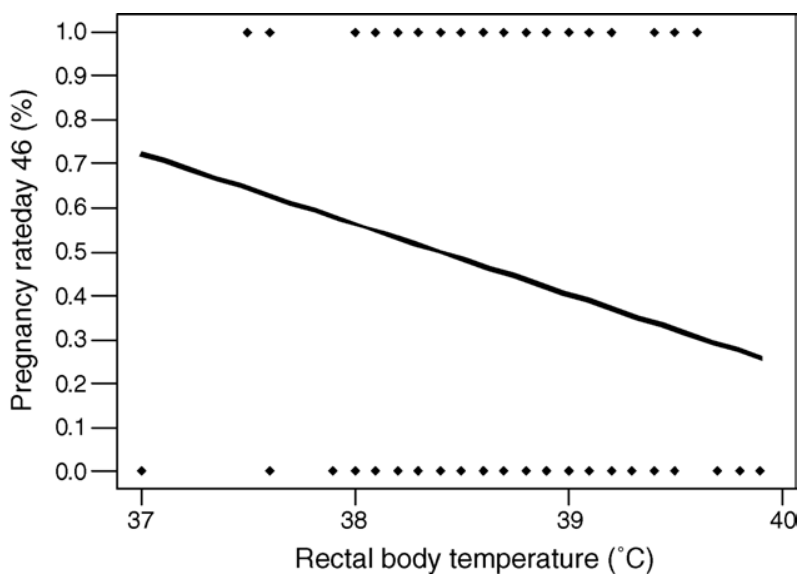

Fig. 6. Effect of rectal body temperature on day of embryo transfer on estimated probability of pregnancy at day 46 in lactating dairy cow recipients (dots are the distribution of events: $0=$ not pregnant; $1=$ pregnant). 


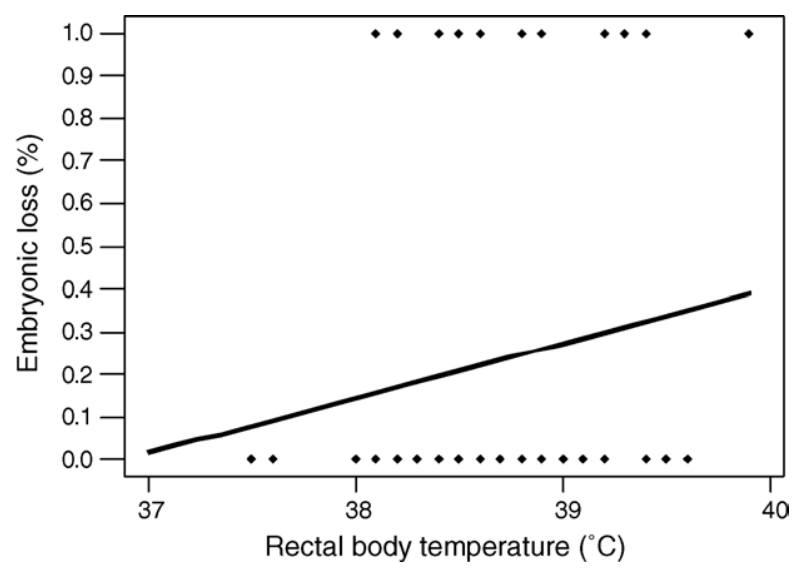

Fig. 7. Effect of rectal body temperature on day of embryo transfer on estimated probability of embryonic loss in lactating dairy cow recipients (dots are the distribution of events: $0=$ no embryonic loss; $1=$ embryonic loss).

Average daily milk production from day of ET to 7 days later influenced embryonic loss. The antagonistic relationship between milk yield and fertility has been reported in several studies $[19,20]$. The effect of high milk yield on fertility in lactating dairy cow recipients suggests that this effect can occur also after embryo reaches the blastocyst stage.

Heat stress can compromise the reproductive events required to embryo development by decreasing expression of estrus behavior, altering follicular growth, compromising oocyte competence, and inhibiting embryonic development [21]. Embryo transfer is a strategy that bypasses effects of heat stress during the period of follicular development and the first 7 days of embryonic development. Oocyte and embryos at early stages are extremely sensitive to heat stress, while embryos 3 days and older are thought to be more resistant [22]. Our data show that temperature effects seems to persist for more than 3 days after fertilization, since body temperature on the day of embryo transfer had an effect on pregnancy rates and embryonic loss. Either the embryo retains sensitivity to heat stress at day 7 or heat stress effects on the reproductive tract lead to pregnancy failure.

In the present experiment, non-lactating cows are used as donors, so there was little effect of heat stress and milk yield on embryo quality. Lactating cows are more sensitive to high temperatures due to the heat generated by increased metabolism associated with high feed intake and milk production [23]. Sartori et al. [16] reported that lactating cows had greater increase in body temperature in response to increases in environmental temperature than was observed in heifers. In this experiment the average milk production from 7 days before $\mathrm{PGF}_{2 \alpha}$ injection to 7 days after ET had tendency $(P=0.08)$ to influence rectal body temperature on day of embryo transfer. Studies suggest a negative interaction between milk production and heat stress on reproductive performance of dairy cows [20].

Diseases during early postpartum period are known to affect reproductive performance of lactating dairy cows [7]. This could be one of the reasons why pregnancy rate is higher as DIM increases. 
In conclusion, the influence of high milk yield and body temperature on fertility in lactating dairy cow recipients suggests that these effects can occur also after embryo reaches the blastocyst stage. Embryo transfer using fresh embryos could be used as a tool to maintain high pregnancy rates in lactating dairy cows.

\section{Acknowledgements}

This research was supported by Agrindus SA and Samvet Embrioes.

\section{References}

[1] Cartmill JA, El Zarkouny SZ, Hensley BA, Lamb GC, Stevenson JS. Stage of cycle, incidence, and timing of ovulation, and pregnancy rates in dairy cattle after three timed breeding protocols. J Dairy Sci 2001; 84:1051-9.

[2] Gröhn YT, Rajala-Schultz PJ. Epidemiology of reproductive performance in dairy cows. Anim Reprod Sci 2000;60/61:605-14.

[3] Hansen PJ, Aréchiga CF. Strategies for managing reproduction in the heat-stressed dairy cow. J Anim Sci 1999;77:E37-50.

[4] Lucy MC. Reproductive loss in high-producing dairy cattle: where will it end? J Dairy Sci 2001;84:1277-93.

[5] Moreira F, Orlandi C, Risco CA, Mattos R, Lopes F, Thatcher WW. Effects of presynchronization and bovine somatotropin on pregnancy rates to a time artificial insemination protocol in lactating dairy cows. J Dairy Sci 2001;84:1646-59.

[6] Santos JEP. Juchem SO, Cerri RLA. Galvão KN, Chebel RC, Thatcher WW, et al. Effect of bST and reproductive management on reproductive and lactational performance of Holstein dairy cows. J Dairy Sci 2004;87:868-81.

[7] Chebel RC, Santos JEP, Reynolds JP, Cerri RLA, Juchem SO, Overton M. Factors affecting conception rate after artificial insemination and embryonic loss in lactating dairy cows. Anim Reprod Sci 2004;84:239-55.

[8] Hansen PJ, Arechiga CF. Strategies for managing reproduction in heat-stressed dairy cows. J Anim Sci 1999;77(Suppl 2):37-50.

[9] Lohuis MM. Potential benefits of bovine embryo-manipulation technologies to genetic improvement programs. Theriogenology 1995;43:51-60.

[10] Drost M, Ambrose JD, Thatcher M-J, Cantrell CK, Wolfsdorf KE, Hasler JF, et al. Conception rates after artificial insemination or embryo transfer in lactating dairy cows during summer in Florida. Theriogenology 1999;52:1161-7.

[11] Rutledge JJ. Use of embryo transfer and IVF to bypass effects of heat stress. Theriogenology 2001;55:10511.

[12] Al-Katanani YM, Drost M, Monson RL, Rutledge JJ, Krininger III CE, Block J, et al. Pregnancy rates following timed embryo transfer with fresh or vitrified in vitro produced embryos in lactating dairy cows under heat stress conditions. Theriogenology 2002;58:171-82.

[13] Robertson I, Nelson RE. Certification and identification of the embryo. In: Stringfellow DA, Seidel SM., editors. Manual of the international embryo transfer society. Int Embryo Transfer Soc; 1998. p. 103-34.

[14] MINITAB. Reference manual release 13.32. State College, PA: MINITAB Inc.; 2000.

[15] López-Gatius F, López-Bèjar M, Fenech M, Hunter RHF. Ovulation failure and double ovulation in dairy cattle: risk factors and effects. Theriogenology 2005;63:1298-307.

[16] Sartori R, Sartor-Bergfelt R, Mertens SA, Guenther JN, Parrish JJ, Wiltbank MC. Fertilization and early embryonic development in heifers and lactating cows in summer and lactating and dry cows in winter. $\mathrm{J}$ Dairy Sci 2002;85:2803-12.

[17] Bode ML, Gilbert RO, Butler WR. Effects of high plasma urea nitrogen levels on bovine embryo quality and development. J Dairy Sci 2001;84(Suppl 1):116. 
[18] Sartori R, Gumen A, Guenther JN, Souza AH, Caraviello DZ, Witbank MC. Comparison of artificial insemination versus embryo transfer in lactating dairy cows. Theriogenology, in press, corrected proof, available online 13 October 2005.

[19] Badinga L, Collier RJ, Wilcox CJ, Thatcher WW. Interrelationships of milk yield, body weight and reproductive performance. J Dairy Sci 1985;68:1828-31.

[20] Al-Katanami YM, Webb DW, Hansen PJ. Factors affecting seasonal variation in 90-day non-return rate to first service in lactating Holstein cows in a hot climate. J Dairy Sci 1999;82:2611-6.

[21] Hansen PJ, Drost M, Rivera RM, Paula-Lopes FF, Al-Katanami YM, Krininger III CE, et al. Adverse impact of heat stress on embryo production: causes and strategies for mitigation. Theriogenology 2001;55:91-103.

[22] Ealy AD, Drost M, Hansen PJ. Developmental changes in embryonic resistance to adverse effects of maternal heat stress in cows. J Dairy Sci 1993;76:2899-905.

[23] Fuquay JW. Heat stress as it affects animal production. J Anim Sci 1981;52:164-74. 